\title{
A Rare Presentation of ph Chromosome: idic der (22q11) in Blast Crisis Chronic Myeloid Leukemia
}

Kumari $\mathbf{P}^{1 *}$, Mangalagowri $\mathbf{M}^{1}$, Kavitha $\mathrm{BL}^{1}$, Obula Reddy $\mathrm{C}^{1}$, Shanthala $\mathbf{S}^{1}$, Mahadavaprasad $\mathbf{M}^{1}$, Madhumathi DS ${ }^{2}$ and Govinda $\mathrm{BK}^{3}$

${ }^{1}$ Department of Cytogenetics, Kidwai Memorial Institute of Oncology, Bangalore, India

${ }^{2}$ Department of Hematology, Kidwai Memorial Institute of Oncology, Bangalore, India

${ }^{3}$ Department of Medical Oncology, Kidwai Memorial Institute of Oncology, Bangalore, India

*Corresponding author: Kumari P, Associate Professor in Cytogenetics, Head of the Cytogenetics Unit, Department of Pathology, Kidwai Memorial Institute of Oncology, Bangalore, India, Tel: +9901153365; E-mail: prasannakumari@yahoo.com

Received date: October 14, 2018; Accepted date: November 13, 2018; Publication date: November 20, 2018

Copyright: () 2018 Kumar P, et al. This is an open-access article distributed under the terms of the Creative Commons Attribution License, which permits unrestricted use, distribution, and reproduction in any medium, provided the original author and source are credited.

\begin{abstract}
The ider(22)t(9;22)(q34; q11) is a rare secondary karyotypic abnormality of $\mathrm{Ph}$ chromosome positive chronic myeloid leukemia associated with disease progression, poor clinical outcome and short survival in most of the previously reported cases. The present case of $C M L$ with idic $\operatorname{der}(22) t(9 ; 22)(q 34 ; q 11)$ or idic der $\mathrm{Ph}$ with hybrid transcript ratio of BCR-ABL being $97 \%$ showed a complex karyotype: 48,XY,+8,t(9;22)(q34;q11)i dic(22)(q11),+idic $\operatorname{der}(22) t(9 ; 22)(q 34 ; q 11)$. On treatment with Imatinib the initial transcript ratio was reduced to $12.125 \%, 0.932 \%$ but later increased to $93 \%$. The patient developed extra medullary myeloid cell tumor of testis after a year of treatment followed by the detection of T3151 mutation. Cytogenetics provides an evidence for progression of disease at an earlier phase than other markers in this case.
\end{abstract}

Keywords: Chronic myeloid Leukemia; idic der Ph; Imatinib; Karyotype; Prognosis

\section{Introduction}

Chronic myeloid leukemia (CML) is genetically characterized by the presence of the reciprocal translocation $\mathrm{t}(9 ; 22)(\mathrm{q} 34 ; \mathrm{q} 11)$, resulting in a BCR-ABL gene fusion on the derivative chromosome 22 called Philadelphia chromosome (Ph) in $90 \%-95 \%$ of patients. [1] In 5\%-10\% of patients, variant translocation and masked $\mathrm{Ph}$ chromosome were reported [2-7] Furthermore, rearrangements in $\mathrm{Ph}$ chromosome like iso, dicentric and amplified or multiple $\mathrm{Ph}$ chromosomes are rarely reported in literature [8-11]. we present a case of CML with idic der Ph chromosome from a young male. The genesis and clinical outcome of the same is discussed in detail with reference to the available literature.

\section{Case History}

A 36-year-old male patient presented in December 2006 with a past history of being treated elsewhere as CML, with hydroxyurea for four years. Clinically patient was asymptomatic. Detailed investigations done in our centre revealed: $\mathrm{Hb}$ of $125 \mathrm{grams} / \mathrm{L}$, raised WBC count of $100 \times 10^{9} / \mathrm{L}$ and platelet count of $23.6 \times 10^{9} / \mathrm{L}$. The differential count of blood and Bone Marrow Aspirate (BMA) findings were suggestive of CML in Chronic Phase. The cytogenetic analysis from BMA revealed two abnormal clones with karyotypes :46,XY,t(9;22)(q34;q11) [2] and $47, X Y, t(9 ; 22)(q 34 ; q 11),+i d i c \quad \operatorname{der}(22) t(9 ; 22)(q 34 ; q 11) \quad[12-15]$ suggesting CML in Blast Crisis. The ratio of Bcr-Abl/Abl transcript by RT-PCR was detected to be $97 \%$ in leukocytes of the peripheral blood. The patient was treated with Imatanib mesylate (Glivec) $400 \mathrm{mg}$. Initially he responded to therapy, the ratio of $\mathrm{Bcr}-\mathrm{Abl} / \mathrm{Abl}$ transcript was gradually reduced to $12.125 \%$ and $0.932 \%$ in the interval of 3 and 5 months respectively. Qualitative analysis of Imatinib Resistance mutations screened in Abl kinase domain of Bcr-Abl transcript revealed no mutations.

In December 2007, he developed left testicular swelling, the biopsy showed perivascular infiltration by population of cells having round vesicular nuclei, moderate cytoplasm and prominent nucleolus. A few eosinophils were also noted. Immunohistochemistry was performed on the testicular biopsy, revealed the neoplastic cells to be positive for $C D 68, M P O$ and negative for $C D 34, C D 117$. A diagnosis of extra medullary Myeloid cell tumor of testis -Blastic type was made. Then the dosage of imatinib was increased to $600 \mathrm{mg}$.

In August 2008 his $\mathrm{Hb}$ was 119 grams/L, WBC 57.7 x 10 9/L and platelates 19.4 x 10 9/L. Hypercellular marrow with marked myeloid hyperplasia, with increase in early myeloid precursors, increase in basophiles (4\%) and micromegakarycytes were noted. It was reported as CML not in remission. The karyotype: $47, \mathrm{XY}, \mathrm{t}(9 ; 22)(\mathrm{q} 34 ; \mathrm{q} 11) \mathrm{idic}$ $\operatorname{der}(22)(\mathrm{q} 11)$, +idic $\operatorname{der}(22) \mathrm{t}(9 ; 22)(\mathrm{q} 34 ; \mathrm{q} 11)$ (32) was observed without standard ph chromosome (Figure 1). The Abl/Abl transcript was found to be $97 \%$ and mutation was not detected. Patient was shifted to tablet Dasatinib $100 \mathrm{mg}$ OD. His tolerance to this drug was not good, he had intolerable diarrhea and did not wanted to continue the same. Patient was shifted back to hydroxyurea and Imatinib $600 \mathrm{mg}$.

In September 2010 his $\mathrm{Hb}$ was 130 grams /L, WBC $30.2 \times 109 / \mathrm{L}$ and platelates $27 \times 109 / \mathrm{L}$. Surprisingly marrow was in hematological remission, but complex karyotype 48,XY,+8,t $(9 ; 22)(\mathrm{q} 34 ; \mathrm{q} 11)$ idic der (22)(q11),+idic der (22)t(9;22)(q34;q11) (25) was observed. Bcr$\mathrm{Abl} / \mathrm{Abl}$ transcript was $90 \%$ and he was planned for a trail of Nilotinib. Meanwhile in October 2010 the mutation T3151 (Thr to IIe) was detected. Based on these findings the patient was advised for Bone Marrow Transplantation, awaiting allogeneic bone marrow transplantation from his HLA-matching sibling. Later the patient was lost for follow-up. 


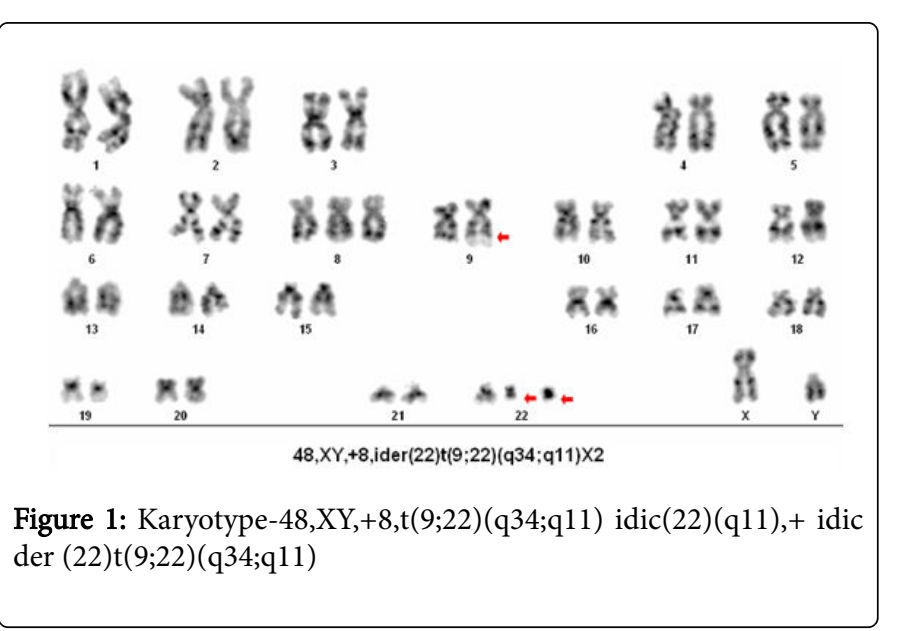

\section{Discussion}

The available literature reveals that $\mathrm{CML}$ with idic der $\mathrm{Ph}$ chromosome were failed to respond to imatinib treatment $[9,14,15]$ Further, Patients who are not responding to Imatinb were more likely to develop additional karyotypic changes during the course of the disease [15]. As the disease evolves from chronic phase to blast crisis in $\mathrm{CML}$, it is accompanied by recurring secondary chromosomal abnormalities such as $+\mathrm{Ph},+8,+19, \mathrm{i}(17)(\mathrm{q} 10) \quad[7,11]$. These abnormalities occur as sole or in combination. Trisomy 8 probably occurred before the transformation or it was present in chronic phase or accelerated phase predominantly in myeloid series [11] Interesting aspects of our case is the presence of classic Ph clone along with idic der ph chromosome, it accounts for four ph chromosomes and karyotype evolution. During third year of his treatment the karyotype was $48, \mathrm{XY},+8, \mathrm{t}(9 ; 22)(\mathrm{q} 34 ; \mathrm{q} 11)$ idic $\operatorname{der}(22)(\mathrm{q} 11),+\operatorname{idic} \operatorname{der}(22) \mathrm{t}(9 ; 22)$ (q34;q11). In the present case, during karyotype evolution, addition of idic der Ph chromosome occurred initially followed by Trisomy 8 . This patient also did not respond to Imatinib treatment.

Gargallo et al. [12] reported a case with amplification of the $\mathrm{BCR} / \mathrm{ABL}$ fusion gene clustered on masked $\mathrm{Ph}$ chromosome associated with myeloblastic phase developed during the disease progression. Gadzicki et al. [15] gave evidence that the genomic Bcr-Abl amplification results in an increased level of Bcr-Abl transcript and karyotype evolution by acquiring ider (22) linking to two potent mechanisms of resistance against Imatinib treatment. In the present case, although the patient responded to Imatinib initially ( transcript ratio reduced from $97 \%$ to 0.932 with Imatinib $400 \mathrm{mg}$ ), later the cytogenetics (double idic der $\mathrm{Ph}+8$ ) and molecular evidences of relapse (93\%) were noted. The presence of the multiple gene copies of the Bcr-Abl transcript, because of multiple copies of $\mathrm{Ph}$ (idic der ph) seems to be the cause for resistance to Imatinib, despite increased drug dosage.

Most of the iso $\mathrm{Ph}$ or idic $\mathrm{Ph}$ chromosome reported in the literature have been described to be a fusion occurring at the $\mathrm{p}$ arms at band p13, resulting in multiple copies of the fusion oncogene $[13,14]$. Li et al. [9] described a rare case of an ider (22) formed by a fusion in the $q$ arm at $\mathrm{q} 11$ in the absence of classic Ph chromosome and lack of mutation at Imatinib binding region on the fusion product with a short survival. In our case it may be of the former type.

A few studies revealed Bcr-Abl kinase domaine mutations in CML that have been detected in association with clinical resistance to
Imatinib and no cytogenetic response [12,14-18]. Thus, the studies suggest that Imatinib resistant mutation should be included in the management of CML patients together with molecular, cytogenetic and clinical monitoring. In the present case, complex karyotype and high Bcr-Abl/Abl transcripts were detected from the beginning but mutation T3151 was detected later. Cytogenetic studies often provide evidence of progression of disease at an earlier phase than other markers.

\section{References}

1. Rowley JD (1973) Letter: A new consistent chromosomal abnormality in chronic myelogenous leukemia identified by quinacrine fluorescence and Giemsa staining. Nature 243: 290-293.

2. Huret JL (1990) Complex translocations, simple variant translocations and Ph-negative cases in chronic myelogenous leukemia. Hum Genet 85 : 565-568.

3. Madhavi G, Benn P, Li Z, Fang M (2007) On the genesis and prognosis of variant translocations in chronic myeloid leukemia. Cancer Genetics and Cytogenetics 173: 97-106.

4. O'Brien S, Thall PF, Siciliano MJ (1997) Cytogenetics of chronic myelogenous leukemia. Baillieres Clin Haematol 10: 259-276.

5. El-Zimaity MM, Kantarjian H, Talpaz M, Brien S, Giles F, et al. (2004) Results of imatnib mesylate therapy in chronic myelogenous leukemia with variant Philadelphia chromosome. Br J Haematol 125: 187-195.

6. Johanson B, Fioretos T, Mitelman F (2002) Cytogenetic and molecular genetic evolution of chronic myeloid leukemia. Acta Haematol 107: 76-94.

7. Sandberg AA (1980) Chromosomes and causation of human cancer and leukemia: XL. The Ph1 and other translocations in CML. Cancer 46: 2221-2226.

8. Szych CM, Liesveld JL, Iqbal MA, Li L, SiebertS Asmus C, et al. (2007) Isodicentric Philadelphia chromosome in Imatinib Mysylate( Gleevac)resistant patients. Cancer Genet Cytogenet 174: 132-137.

9. Li Ming chua C, Tan YY, Chua SP, Ma HB, Koay E, et al. (2010) Multiple copies of a rare rearrangement of Philadelphia chromosome in a chronic myeloid leukemia patient: a case report. Cancer Genet Cytogent 199: 66-68.

10. Barner DJ, Palaiogai D, Panousopoular E, Schultheis B, Yang AS, et al. ( 2005) Chronic myeloid leukemia. Cancer Re 65: 8912-8919.

11. Pratibha SA (2002) Chronic myeloid leukemia: Cytogenetics and molecular genetics. Indian J Hum Genet 8: 4-10.

12. Gargallo PM, Cuello MT, Araguren PN, Larripa IB (2003) Amplification of the BCR/ABL fusion gene clustered on a masked Philadelphia chromosome in a patient with myeloblastic crysis of chronic myelocytic leukemia. Cancer Genet Cytogenet 143: 140-144.

13. Virgili A, Nacheva EP (2010) Genomic amplification of the BCR/ABL and a region downstream of ABL1 in chronic myeloid leukemia: A FISH mapping study of CML patients and cell lines. Mol Cytogenet 3: 15 .

14. Pernice F, Squadrito G, Saitta A, Mazza G, Musolino C, et al. (1993) Isodicentric Philadelphia chromosome in accelerated phase of chronic myeloid leukemia. Cancer Genet Cytogenet 66: 113-116.

15. Gadzicik D, Von Neuhoff N, Sleinemann D, Just M, Busche G, et al. (2005) BCR/ABL gene amplification and over expression in a patient with chronic myeloid leukemia treated with Imatinib. Cancer Genet Cytogenet 159: 164-167.

16. Schoch T, Haferiach, Kern W, Schnittrer S, Berger U, et al. (2003) Occurrence of additional chromosome aberrations in chronic myeloid leukemia patients treated with imatinib mesylate. Leakemia 17: 461-463.

17. Roche-Lestienne C (2002) Several types of mutations of the Abl gene can be found in chronic myeloid leukemia patients resistant to ST1571, and they can pre-exist. Blood 100: 1014-1018.

18. Passerini CG, Piazza, Maurizio DI (2003) Bcr-Abl mutations, resistance to imatinib, and imatinib plasma levels. Blood 102: 1933-1935. 